\title{
Meal-induced oxygen desaturation and dyspnea in chronic obstructive pulmonary disease
}

\author{
Norman Wolkove MD FCCP, Li Yi Fu MD, Ashok Purohit MD, Antoinette Colacone BSc, \\ Harvey Kreisman MD FCCP \\ Pulmonary Department, Mount Sinai Hospital Center, Côte St Luc, Quebec
}

\begin{abstract}
N Wolkove, LY Fu, A Purohit, A Colacone, H Kreisman. Meal-induced oxygen desaturation and dyspnea in chronic obstructive pulmonary disease. Can Respir J 1998;5(5):361-365.
\end{abstract}

OBJECTIVE: To study arterial oxygen saturation $\left(\mathrm{SpO}_{2}\right)$ obtained by pulse oximetry and dyspnea during active eating (AE) and passive eating (PE) in patients with severe chronic obstructive pulmonary disease (COPD).

DESIGN: Patients were studied on two consecutive days with $\mathrm{AE}$ and $\mathrm{PE}$, which occurred in random order. $\mathrm{SpO}_{2}$ was recorded for 20 mins before and during eating, and dyspnea was recorded by the patient using a $10 \mathrm{~cm}$ visual analogue scale before and upon completion of eating.

SETTING: Subjects were in-patients at an intermediate care facility who were hospitalized for pulmonary rehabilitation or for convalescence after an exacerbation of COPD.

POPULATION STUDIED: Thirty-five patients with severe COPD (forced expiratory volume in $1 \mathrm{~s}\left[\mathrm{FEV}_{1}\right]$ less than $50 \%$ predicted, $\mathrm{FEV}_{1}$ to forced vital capacity ratio less than $65 \%$ ) were studied. Mean age was $70.5 \pm 7.1$ years.

MAIN RESULTS: Mean $\mathrm{SpO}_{2}$ decreased significantly $(\mathrm{P}<0.05)$ from $91.7 \pm 3.4 \%$ to $90.1 \pm 4.0 \%$ during $\mathrm{AE}$, and $91.7 \pm 3.2 \%$ to $90.8 \pm 3.6 \%$ during PE. Mean lowest $\mathrm{SpO}_{2}$ was lower and percentage of time with $\mathrm{SpO}_{2}$ less than $90 \%$ was greater during eating compared with corresponding control periods during both $\mathrm{AE}$ and $\mathrm{PE}$. Dyspnea increased significantly $(\mathrm{P}<0.05)$ from $1.4 \pm 1.2$ to $3.3 \pm 2.3 \mathrm{~cm}$ during $\mathrm{AE}$, and from $1.5 \pm 1.5$ to $2.4 \pm 2.2 \mathrm{~cm}$ during PE. The increase in dyspnea was significantly greater during AE than PE.

CONCLUSIONS: Eating is an activity that can adversely affect $\mathrm{SpO}_{2}$ and increase dyspnea in patients with severe COPD. Oxygen desaturation and particularly increased dyspnea may at least in part relate to the recruitment of upper extremity muscles during eating.

Key Words: Chronic Obstructive pulmonary disease, COPD, Meal desaturation, Meal dyspnea, Oxygen desaturation

\section{Désaturation de l'oxygène et dyspnée induites par la prise de repas dans la MPOC}

OBJECTIF : Étudier la saturation du sang artériel en oxygène $\left(\mathrm{SpO}_{2}\right)$ et la dyspnée durant la prise active de repas (PAR) et le repas passif (RP) chez des patients atteints de maladie pulmonaire obstructive chronique grave (MPOC).

MODÈLE : Les patients ont été examinés deux jours consécutifs lors de PAR et lors de RP dans un ordre aléatoire. $\mathrm{La} \mathrm{SpO}_{2}$ a été enregistrée pendant 20 minutes avant et durant la prise d'aliments et la dyspnée a été notée par les patients à l'aide d'une échelle analogique visuelle de $10 \mathrm{~cm}$ avant le repas et à la fin du repas.

CONTEXTE : Les sujets étaient des patients hospitalisés pour une réadaptation pulmonaire ou pour une convalescence après exacerbation d'une MPOC dans un établissement de soins intermédiaires. POPULATION ÉTUDIÉE : Trente-cinq patients atteints de MPOC grave (VEMS inférieur à $50 \%$ de la valeur prévue, ratio VEMS:capacité vitale forcée inférieur à $65 \%$ ) ont été étudiés. L’âge moyen était de 70,5 $\pm 7,1$ ans.

voir page suivante 
PRINCIPAUX RÉSULTATS : $\mathrm{La} \mathrm{SpO}_{2}$ moyenne a diminué significativement $(p<0,05)$ pour passer de $91,7 \pm 3,4 \%$ à $90,1 \pm 4,0$ $\%$ durant la PAR et de 91,7 $\pm 3,2$ à 90,8 $\pm 3,6$ durant le RP. $\mathrm{La} \mathrm{SpO}_{2}$ moyenne la plus basse a été inférieure et le pourcentage de temps où la $\mathrm{SpO}_{2}$ a été inférieure à $90 \%$ a été plus longue durant la prise de repas en comparaison avec des périodes témoins correspondantes, tant durant la PAR que le RP. La dyspnée a augmenté significativement $(p<0,05)$, passant de $1,4 \pm 1,2$ à $3,3 \pm 2,3 \mathrm{~cm}$ durant la PAR et de $1,5 \pm 1,5$ à $2,4 \pm 2,2 \mathrm{~cm}$ durant le RP. L'augmentation de la dyspnée a été significativement plus marquée durant la PAR que durant le RP.

CONCLUSIONS : Manger est une activité qui peut altérer la $\mathrm{SpO}_{2}$ et accroître la dyspnée chez les patients atteints de MPOC grave. La désaturation en oxygène et particulièrement l'accroissement de la dyspnée peuvent, en partie du moins, avoir trait à la mise à contribution des muscle des membres supérieurs durant le repas.
$\mathrm{P}$ atients with chronic obstructive pulmonary disease (COPD) often complain of dyspnea and may experience oxygen desaturation with activities of daily living (1). Eating is an activity common to all individuals. Although modest degrees of desaturation have been shown to occur with eating, the mechanism by which this occurs remains speculative. Meal-related dyspnea has not been evaluated comprehensively in a prospective fashion. In this study we examined oxygen desaturation and dyspnea during eating in patients with COPD. Our aim was to determine the extent to which the phenomena occurred during eating and whether desaturation and/or dyspnea is related to upper extremity use in this specific activity. To elucidate the latter, we measured oxygen saturation and dyspnea in patients with severe COPD eating normally and while being fed.

\section{PATIENTS AND METHODS}

Patients: Thirty-five patients with severe COPD were studied (Table 1). All subjects were former cigarette smokers with a clinical history consistent with COPD; patients were eligible for inclusion if they had a forced expiratory volume in $1 \mathrm{~s}\left(\mathrm{FEV}_{1}\right)$ less than $50 \%$ predicted and an $\mathrm{FEV}_{1}$ to forced vital capacity (FVC) ratio less than $65 \%$. All patients were clinically stable and were studied while hospitalized at Mount Sinai Hospital, Côte St Luc, Quebec for a pulmonary rehabilitation program or for convalescence after a recent exacerbation of COPD. Patients admitted to the study were required to have a resting transcutaneous arterial oxygen saturation $\left(\mathrm{SpO}_{2}\right) 85 \%$ or greater on room air. Those receiving supplemental oxygen needed to have that withheld for at least $2 \mathrm{~h}$. Routine spirometry was performed, and FEV 1 and FVC recorded on the best of three expiratory efforts using an electronic spirometer (Vitalograph Model 42.000 Type C, Vitalograph Ltd, Buckingham, United Kingdom). The study

\begin{tabular}{lc} 
TABLE 1 \\
Characteristics of patients with chronic obstructive \\
pulmonary disease included in meal-induced oxygen \\
desaturation and dyspnea study \\
\hline Number of patients & 35 \\
Age (years) & $70.5 \pm 7.1$ \\
Sex (male to female) & $22: 13$ \\
Chronic oxygen use & 5 \\
Forced expiratory volume in $1 \mathrm{~s}\left(\mathrm{FEV}_{1}\right)$ & $33.7 \pm 9.7$ \\
$\quad$ (\% predicted) & $42.6 \pm 9.7$ \\
FEV 1 /Forced vital capacity $(\%)$ & $91.8 \pm 3.2$ \\
Baseline oxygen saturation $(\%)$ &
\end{tabular}

Mean $\pm S D$ was approved by the Ethics Committee of Mount Sinai Hospital, and informed consent was obtained from all participants.

Eating studies: Eating studies were conducted during either the noon or evening meal. Meals were standard hospital fare with no attempt made to control for nutritional or caloric content. Patients were studied on two consecutive days, with active eating (AE) and passive eating (PE) occurring in random order. During AE, patients ate normally at their own speed. During PE, patients were seating comfortably with hands on their laps and were fed by a research assistant. Continuous monitoring and computerized recording of $\mathrm{SpO}_{2}$ using a pulse oximeter (Ohmeda Biox 3700, Colorado) was obtained before and during eating. The recording electrode was placed on the left middle finger and sealed with tape to secure the sensor. A pilot study had shown that meals were usually completed within 20 mins. Therefore, the control premeal period was always 20 mins. The patient sat comfortably in a chair during this time before commencing the eating study. $\mathrm{SpO}_{2}$ monitoring was terminated when the meal was completed. Patients were asked to record dyspnea using a $10 \mathrm{~cm}$ visual analogue scale before and upon completion of eating.

Measurements and definitions: Premeal or control saturation was the average $\mathrm{SpO}_{2}$ for each patient during the $20 \mathrm{~min}$ control period. A mean pre-eating $\mathrm{SpO}_{2}$ was then calculated for the 35 patients; this was used in analyzing the results (mean $\mathrm{SpO}_{2}$ :control). Similarly, eating saturation was defined as the average $\mathrm{SpO}_{2}$ during the meal period for each individual, and a mean $\mathrm{SpO}_{2}$ was obtained for the entire study group (mean $\mathrm{SpO}_{2}$ :eating).

Because mean values during sustained activity may not adequately reflect periods of desaturation, two additional determinations were made. The lowest saturation recorded during pre-eating and eating phases was recorded for each subject, and mean values once again obtained for each time period (mean lowest $\mathrm{SpO}_{2}$ ). Finally, in every subject, the percentage of time with saturation less than $90 \%$ during control and meal periods was taken. As with other measurements, mean data were used for comparisons (percentage of time with $\mathrm{SpO}_{2}$ less than 90\%). This threshold was chosen because it was felt that values below that level could be significant clinically.

Statistical analysis: Data analysis was performed using the StatView statistical package (Abacus Concepts, California). ANOVA was used to evaluate the changes in oxygen saturation and dyspnea before and during the meal. The grouping factors employed were method of eating and severity of obstruction. Parametric and nonparametric tests were applied to 
TABLE 2

Changes in oxgyen saturation $\left(\mathrm{SpO}_{2}\right)$ with active eating $(\mathrm{AE})$ and passive eating (PE)

\begin{tabular}{lcccc}
\hline & & AE & & PE \\
& Control & Eating* & Control & \multicolumn{1}{c}{ Eating* } \\
\hline Mean $\mathrm{SpO}_{2}$ & $91.7 \pm 3.4$ & $90.1 \pm 4.0$ & $91.7 \pm 3.2$ & $90.8 \pm 3.6$ \\
Mean lowest $\mathrm{SpO}_{2}$ & $88.9 \pm 4.1$ & $87.0 \pm 4.3$ & $89.1 \pm 4.6$ & $87.7 \pm 4.4$ \\
Percentage of time with $\mathrm{SpO}_{2}$ less than $90 \%$ & $19.3 \pm 34.0$ & $33.7 \pm 42.6$ & $18.5 \pm 33.5$ & $27.8 \pm 40.2$ \\
\hline
\end{tabular}

Results presented as mean $\pm S D$. * Significant differences occurred between control and eating periods during both $A E$ and $P E(P<0.05)$. Change in mean $\mathrm{SaO}_{2}$ was significantly greater during $A E$ versus $P E(P<0.05)$

TABLE 3

Changes in oxygen saturation $\left(\mathrm{SpO}_{2}\right)$ in chronic obstructive pulmonary disease (COPD) patients with forced expiratory volume in $1 \mathrm{~s}\left(\mathrm{FEV}_{1}\right)$ greater than $35 \%$ predicted (group $\mathrm{A}, \mathrm{n}=17$ ) and $\mathrm{FEV}_{1}$ less than $35 \%$ predicted (group $\mathrm{B}, \mathrm{n}=18$ )

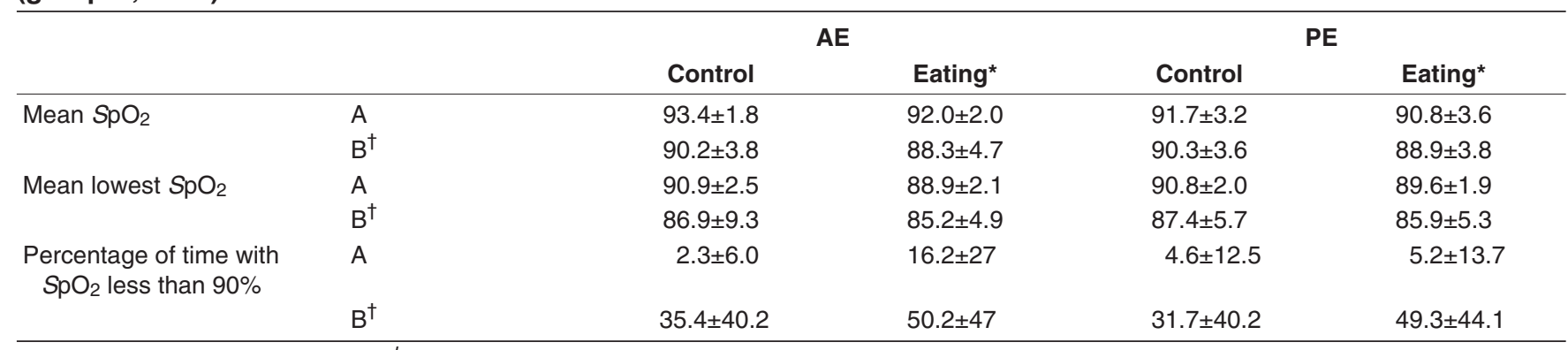

Results presented as mean $\pm S D .{ }^{\dagger}$ Baseline mean values between groups $A$ and $B$ were significantly different $(P<0.05)$. ${ }^{*}$ Mean values changed significantly between control and eating periods during both active eating $(A E)$ and passive eating $(P E)(P<0.05)$ for groups $A$ and $B$. Mean $S p O_{2}$ and mean lowest $\mathrm{SpO}_{2}$ were lower and percentage of time with $\mathrm{SpO}_{2}$ less than $90 \%$ was greater in the patients with more severe COPD during eating. However, the changes with eating were not significantly greater in the more severe patients (group $A$ versus group B)

TABLE 4

Dyspnea score during eating $(\mathrm{cm})$ for groups $A$ and $B$

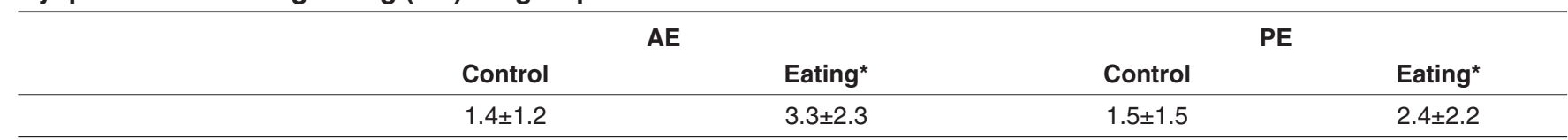

Results presented as mean $\pm S D$. *Dyspnea increased significantly during the eating periods for both $A E$ and $P E(P<0.05)$. Increase in reported dyspnea was greater during active eating $(A E)$ than during passive eating $(P E)(P<0.05)$

assess the differences in continuous variables only when the ANOVA results were significant. $\mathrm{P}<0.05$ was deemed significant. Data are presented as mean \pm SD unless otherwise specified.

\section{RESULTS}

As outlined above, premeal control saturation was always recorded during a standardized $20 \mathrm{~min}$ period. The mean duration of $\mathrm{AE}$ and $\mathrm{PE}$ during which oxygen variables were recorded was $18.0 \pm 3.8$ and $18.4 \pm 4.2$ mins, respectively.

Table 2 shows the changes in $\mathrm{SpO}_{2}$ with $\mathrm{AE}$ and PE. During both $\mathrm{AE}$ and $\mathrm{PE}$, there was a small but statistically significant $(\mathrm{P}<0.05)$ decline in mean $\mathrm{SpO}_{2}$ during eating. The change in mean $\mathrm{SpO}_{2}$ with meals was significantly greater $(\mathrm{P}<0.007)$ during $\mathrm{AE}$ than $\mathrm{PE}$, but the magnitude of the difference was small. Similarly, during both $\mathrm{AE}$ and PE mean lowest $\mathrm{SpO}_{2}$ was lower and percentage of time with $\mathrm{SpO}_{2}$ less than $90 \%$ higher during eating compared with control periods $(\mathrm{P}<0.05)$. For these variables, the significant changes observed with eating were similar in magnitude for $\mathrm{AE}$ and PE conditions.

To determine whether severity of COPD influenced the degree of desaturation with eating, the study population was subdivided into two groups. Group A, consisting of 17 patients with an $\mathrm{FEV}_{1}$ greater than 35\% predicted, was compared with group B, 18 patients with an $\mathrm{FEV}_{1}$ less than $35 \%$ predicted (Table 3). Those with more severe COPD (group B) had lower control values for mean $\mathrm{SpO}_{2}$ and mean lowest $\mathrm{SpO}_{2}$ as well as a higher percentage of time with $\mathrm{SpO}_{2}$ less than $90 \%(\mathrm{P}<0.003)$. For both groups, mean values for all three oxygen parameters measured changed significantly between control and eating periods during both $\mathrm{AE}$ and $\mathrm{PE}$ $(\mathrm{P}<0.001)$. Although mean $\mathrm{SpO}_{2}$ and mean lowest $\mathrm{SpO}_{2}$ were lower and percentage of time with $\mathrm{SpO}_{2}$ less than $90 \%$ was greater in group B during eating, this was likely because of differences in baseline values. The actual changes in the parameters with eating, during either $\mathrm{AE}$ or $\mathrm{PE}$, were similar for groups A and B.

Table 4 documents the dyspnea scores in patients during control periods as well as during AE and PE. Dyspnea increased significantly during both $\mathrm{AE}$ and $\mathrm{PE}(\mathrm{P}<0.001)$. However, the increase in reported dyspnea was greater during $\mathrm{AE}$ than $\mathrm{PE}(\mathrm{P}<0.05)$. Dyspnea scores were also analyzed for the patients grouped as described above by severity 
TABLE 5

Dyspnea scores during eating $(\mathrm{cm})$ for chronic obstructive pulmonary disease patients with forced expiratory volume in $1 \mathrm{~s}\left(F E V_{1}\right)$ greater than $35 \%$ predicted (group $A, n=17$ ) and $F E V_{1}$ less than $35 \%$ predicted (group $\left.B, n=18\right)$

\begin{tabular}{lllll}
\hline Group & Control & Active eating & \multicolumn{2}{c}{ Passive eating } \\
\hline A & $1.6 \pm 1.2$ & Eating $^{*}$ & Control & Eating $^{*}$ \\
B & $1.3 \pm 1.3$ & $3.2 \pm 2.0$ & $1.5 \pm 1.6$ & $2.3 \pm 2.1$ \\
\hline
\end{tabular}

All results present as mean $\pm S D$. Baseline dyspnea was not significantly different between groups $A$ and $B(P=0.86)$. ${ }^{*}$ Mean dyspnea scores changed significantly between control and eating periods for both $A$ and $B$ during $A E$ and $P E(P<0.05)$. The change in dyspnea scores with either $A E$ or $P E$ was similar in groups $A$ and $B$

(groups A and B). Baseline dyspnea was not significantly different between groups A and B (Table 5). Mean dyspnea scores changed significantly between control and eating periods for both groups A and B during AE and during PE. The change in dyspnea scores with either AE or PE was similar in groups A and B.

\section{DISCUSSION}

In this study, we found a small but statistically significant decrease in oxygen saturation during both $\mathrm{AE}$ and $\mathrm{PE}$ in patients with COPD. Meal-induced desaturation was statistically greater during $\mathrm{AE}$ than $\mathrm{PE}$, but the difference was small in absolute terms. Episodic desaturation may be more significant during eating as evidenced by a lower mean lowest $\mathrm{SpO}_{2}$ during both $\mathrm{AE}$ and $\mathrm{PE}$ compared with corresponding baseline values. All patients also spent more time at saturations below $90 \%$ during eating. We also noted that patients with more severe COPD tend to have more unfavourable oxygen parameters during eating, but this is because they start off at a lower baseline oxygen saturation.

Our findings support and extend those of other investigators who have evaluated meal-related desaturation in patients with COPD (2-5). Flick and Block (1) found significant declines in $\mathrm{SpO}_{2}$ with various activities during continuous daytime monitoring in 10 patients with COPD. In two patients changes in saturation as great as $15 \%$ were found while eating. Brown et al (2) studied $\mathrm{SpO}_{2}$ more systematically during meals in 33 patients with COPD. The patients in that study had more severe COPD than the patients in the present study, and therefore had lower mean values for $\mathrm{FEV}_{1}$ and baseline oxygen saturation compared with those in this study. Similar to our results mean $\mathrm{SpO}_{2}$ decreased significantly, but by only $1.8 \%$ during eating. However, despite this modest decline, there was a subgroup of patients (seven of 33) whose change in $\mathrm{SpO}_{2}$ was $4 \%$ or greater, suggesting clinically significant desaturation. Moreover, meal-related desaturation tended to be more severe in those least able to tolerate such a change, ie, these with a lower baseline $\mathrm{SpO}_{2}$. This contrasts with the present study where we found no difference in the magnitude of meal-related desaturation in patients with more severe versus less severe disease. However, the difference probably relates to the level of baseline $\mathrm{SpO}_{2}$. In the study by Brown et al (2), the 'more severe' subgroup had a mean baseline $\mathrm{SpO}_{2}$ of $83.6 \%$ whereas our 'more severe' COPD patients had a mean baseline $\mathrm{SpO}_{2}$ of $90.2 \%$ (AE) and $90.3 \%$ (PE). Schols et al (3), who also reported greater meal desaturation in hy- poxemic compared with normoxemic patients with COPD, may have reconciled these differences by emphasizing the greater vulnerability of the former individuals owing to the sigmoidal shape of the oxygen dissociation curve.

There are severe possible mechanisms for meal-related desaturation in patients with COPD. The ultimate explanation is probably multifactorial, and must explain the small but significant desaturation during PE in this study and even with nasogastric feeding as shown by Brandstetter et al (6). As well, one must account for the greater effect noted during AE. A decrease in minute ventilation as a result of interrupted breathing related to chewing and swallowing is unlikely because previous studies have shown that desaturation during eating is not associated with an increase in partial pressure of carbon dioxide (4-6). We and others have noted that desaturation occurs relatively soon after the onset of eating $(3,4)$. This mitigates against explaining the changes on the basis of the metabolic effects of food, changes that would require time for digestion and absorption. Several authors have postulated that ventilation perfusion relationships are altered if tidal volume or respiratory frequency is altered during eating, and this alteration may be important in COPD $(2,3)$. However, at least in normal subjects eating and drinking do not appear to affect significantly tidal volume, inspiratory duration, expiratory duration or minute ventilation, although breathing becomes more irregular (7). Finally, it is likely that eating, although usually considered a sedentary activity, is a low intensity exercise in patients with severe COPD. The muscles involved are those of mastication, swallowing and, of course, arm elevation. Couser et al (8) have shown that simple arm elevation in normal subjects is associated with a significant increase in metabolic rate, with increased oxygen uptake and carbon dioxide production. This may at least partially explain the finding of oxygen desaturation during eating and the greater effect of AE than PE.

We also found that dyspnea increased with eating and was greater during $\mathrm{AE}$ than PE. The finding of similar changes in dyspnea with eating in our subjects when grouped according to severity is not surprising because perceived breathlessness varies considerably in these patients and correlation between dyspnea and $\mathrm{FEV}_{1}$ has been shown to be weak in COPD (9).

The observed increased dyspnea even with PE may reflect the work performed during mastication and swallowing or the effect of abdominal distention after eating. It has been shown that during eating there is an irregular pattern of 
breathing and an increase in the volume of ribcage and abdomen, both of which have been postulated to contribute to dyspnea (7). The greater effect of AE may once again be explained by considering eating to be a low level exercise involving the upper extremities. Several studies have shown the importance of arm position on ventilation under different conditions $(8,10,11)$. Even in normal subjects arm elevation results in increased ventilatory and metabolic demands similar to those of mild exercise and a disproportionate increase in the diaphragmatic contribution to the generation of ventilatory pressures (8). This is of particular importance in patients with COPD whose diaphragms are less effective. In such individuals, Celli et al (12) have reported that upper extremity exertion may lead to dyssynchronous thoracoabdominal breathing and dyspnea, possibly due to the extra burden on the diaphragm as accessory muscles are recruited to support the arms and torso.

\section{CONCLUSIONS}

We have shown that eating is an activity that can adversely effect oxygen saturation and increase dyspnea in patients with severe COPD. These changes may at least in part be related to the requirement of upper extremity muscles during eating. Although not addressed in this study, it is conceivable that these events, and in particular meal-related dyspnea, may result in reduced dietary intake and contribute to weight loss in patients with severe COPD.

\section{REFERENCES}

1. Flick MR, Block AJ. Continuous in-vivo monitoring of arterial oxygenation in chronic obstructive lung disease. Ann Intern Med 1977;86:725-30

2. Brown SE, Casciari RJ, Light RW. Arterial oxygen saturation during meals in patients with severe chronic obstructive pulmonary disease. South Med J 1983;76:194-8.

3. Schols A, Mastert R, Cobben N, Soeters P, Wouters E. Transcutaneous oxygen saturation and carbon dioxide tension during meals in patients with chronic obstructive pulmonary disease. Chest 1991;100:1287-92.

4. Castaldo WA, DeGregario B, Brandstetter RD. Mealtime arterial $\mathrm{O}_{2}$ saturation in COPD. South Med J 1983;76:1347. (Lett)

5. Nørregørd O, Larsen B, Dahl R. Meal related changes in dyspnea and arterial blood gases in patients suffering from chronic obstructive pulmonary disease. Eur J Respir Dis 1988;68s. (Abst)

6. Brandstetter RD, Zakkay Y, Gutherz P, Goldberg RJ. Effect of nasogastric feedings on arterial oxygen tension in patients with symptomatic chronic obstructive pulmonary disease. Heart Lung 1988;17:170-2.

7. Smith J, Wolkove N, Colacone A, Kreisman H. Coordination of eating, drinking, and breathing in adults. Chest 1989;96:578-82.

8. Couser JI, Martinez FJ, Celli BR. Respiratory response and ventilatory muscle recruitment during arm elevation in normal subjects. Chest 1992;101:336-40.

9. Wolkove N, Dajcman E, Colacone A, Kreisman H. The relationship between pulmonary function and dyspnea in obstructive lung disease. Chest 1989;96:1247-51.

10. Martinez FJ, Couser JI, Celli BR. Respiratory mechanics and ventilatory muscle recruitment in subjects with severe chronic airflow obstruction (CAO). Am Rev Respir Dis 1991;143:476-80.

11. Banzett R, Topulos G, Leith D, Natios C. Bracing arms increases the capacity for sustained hyperpnea. Am Rev Respir Dis 1988;138:106-9.

12. Celli BR, Rassulo J, Make BJ. Dyssynchronous breathing during arm but not leg exercise in patients with chronic airflow obstruction. N Engl J Med 1986;314:1485-90. 


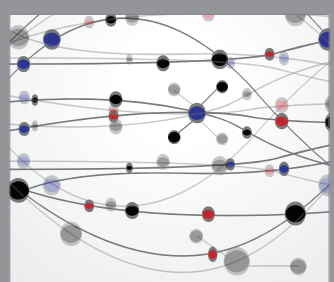

The Scientific World Journal
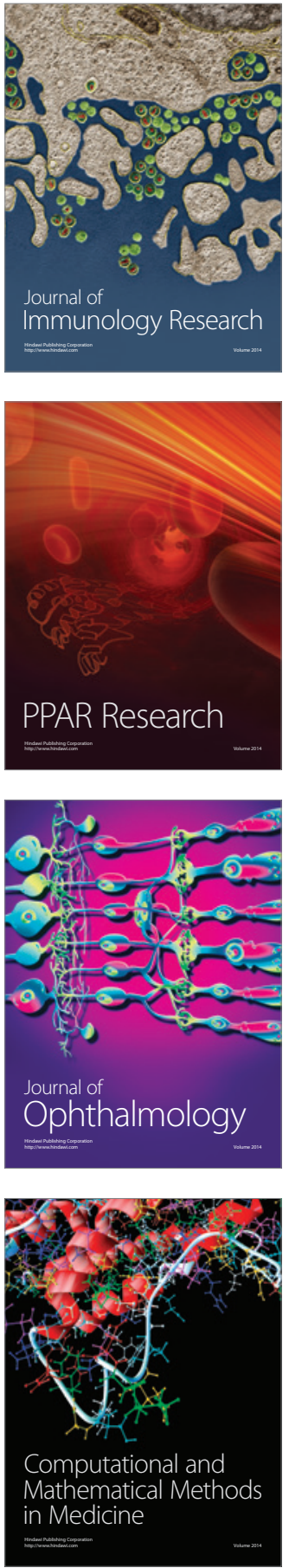

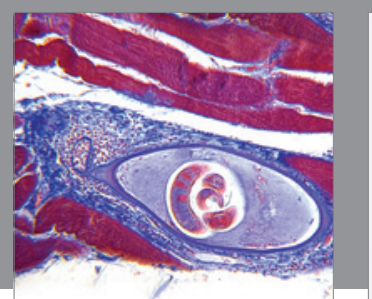

Gastroenterology Research and Practice

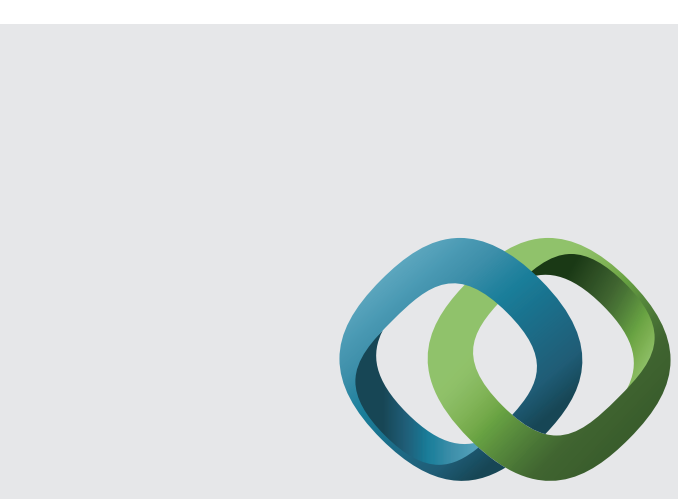

\section{Hindawi}

Submit your manuscripts at

http://www.hindawi.com
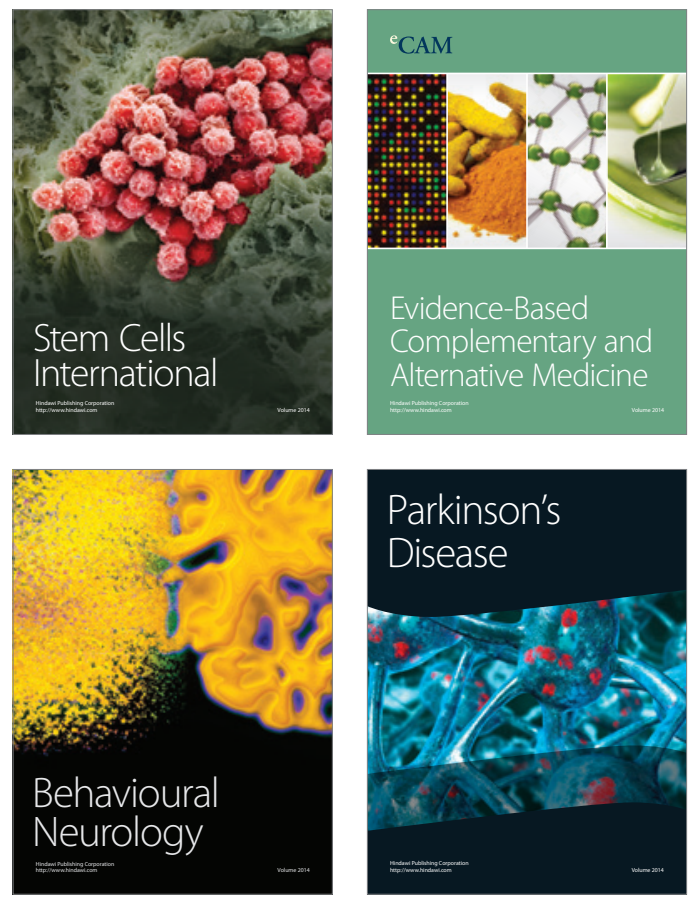
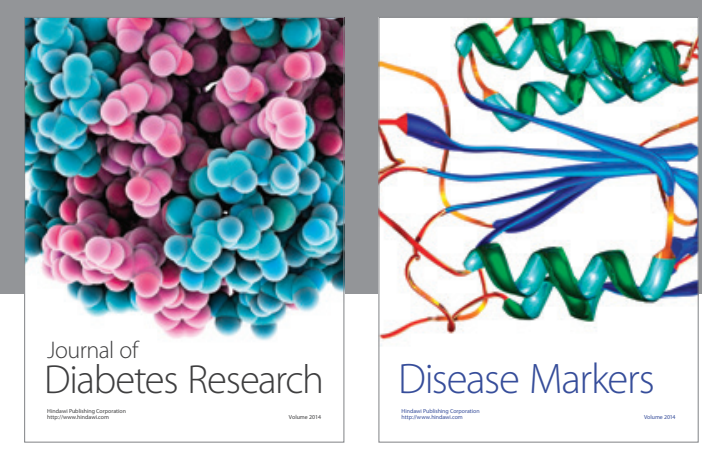

Disease Markers
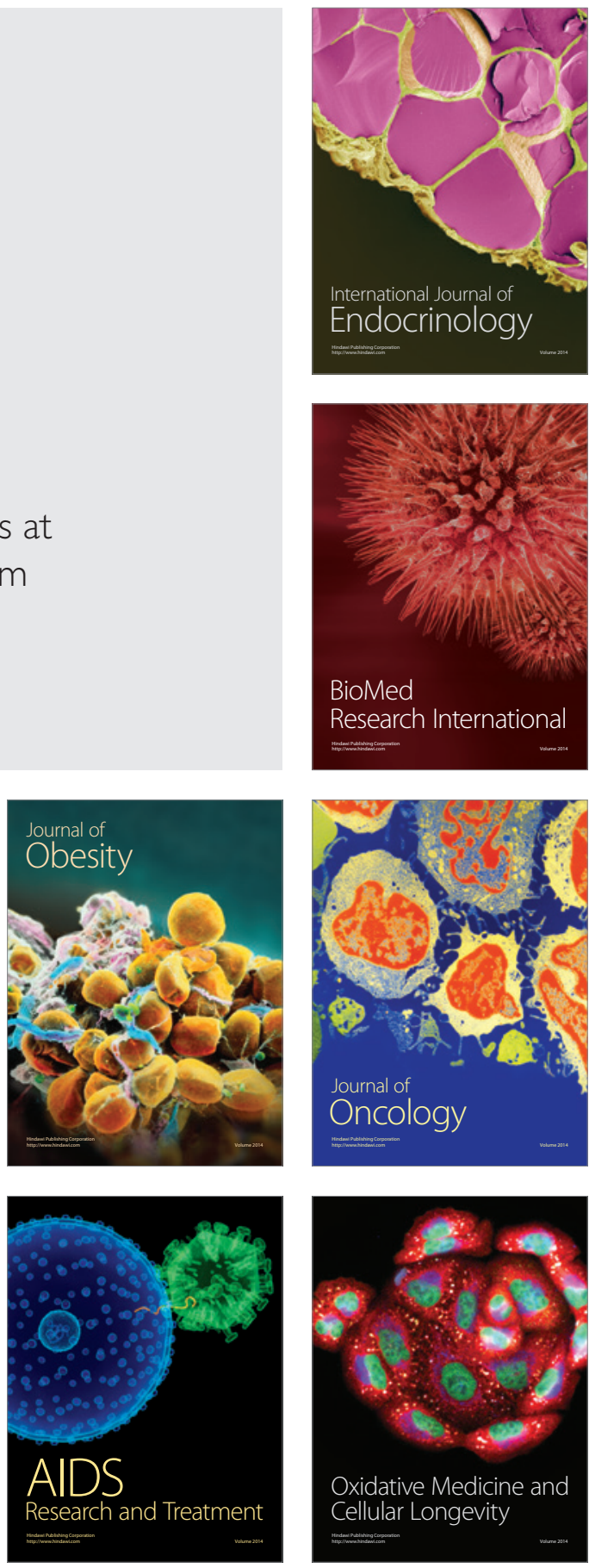